\title{
NEW PERSPECTIVE ARTICLE \\ De Black a la Cariología Contemporánea: Aprendiendo a mirar las mismas lesiones desde otra perspectiva
}

\section{From Black to Contemporary Cariology: Learning to Look at the Same Lesions with a Different Perspective}

\author{
Received: 30-XI-2015 A ccepted: 04-XII-2015 Published Online First: 11-XII-2015
}

DOI: http://dx.doi.org/10.15517/ijds.v0i0.22501

\begin{abstract}
RESUMEN
Desde su nacimiento como profesión y durante los siglos XIX y XX, las Ciencias Odontológicas generaron cantidad abrumadora de nuevo conocimiento en Cariología en áreas tan dispares como las ciencias básicas, la microbiología, los factores endógenos nutricionales y las acciones exógenas alimentarias, la ingeniería y regeneración de tejidos, las ciencias sociales, etc., así como también en la prevención, diagnóstico, clasificación, actividad, monitoreo, control, tratamiento y rehabilitación de las lesiones cariosas. Sin embargo, según reportes del Centro de Control de Enfermedades de USA (1), el problema subyacente sigue vigente: la caries dental continúa, hasta el día de hoy, siendo la enfermedad crónica más frecuente durante la niñez y es 4 veces más común que el asma en adolescentes de 14 a 17 años, Muchos adultos sufren la enfermedad sin recibir el tratamiento requerido, lo que determina que las lesiones progresen, lo que afecta la calidad de vida de las personas. Este new perspecive article presenta información relevante y actualizada sobre la Cariología del Siglo XXI, que podrá contribuir a reversar el estado descrito.
\end{abstract}

\section{PALABRAS CLAVE}

Cariología, ICDAS, Prevención, Caries dental, ICCMS, Condición de riesgo. 


\section{ABSTRACT}

Since its birth as a profession and in the XIXth and XXth centuries, Dental Sciences generated overwhelming amount of new knowledge in Cariology, in such dispair areas as basic sciences, tissue engineering and regeneration, microbiology, endogenous and exogenous nutritional factors, social sciences, etc., as well as in prevention, diagnosis, classification, activity, control, monitoring, treatment and rehabilitation of carious lesions. However, according to the Centers for Disease Control, USA (1), the problem still remains: in childhood tooth decay is the most common chronic disease, and in teenagers from 14 to 17 years old is 4 times more common than asthma. Many adults suffer the disease without treatment, determining the progression of lesions, fact that affects its quality of life. This new perspective article presents relevant and recent information on the Cariology of the XXI Century, that could help reversing the state described.

\section{KEYWORDS}

Cariology, ICDAS, Prevention, Dental caries, ICCMS, Caries risk assessment.

Según reporta Slavkin (2), en 1677 un comerciante holandés llamado Antony van Leeuwenhoek (1632-1723) construyó microscopios simples a partir de lupas que permitían un incremento de 200 veces el tamaño original. Con ellos estudió la vida microscópica existente en una gota de agua, en la saliva de la cavidad oral humana $y$ en los intestinos de una rana. En los siglos siguientes se desarrollaron microscopios cada vez más potentes, lo que resultó en el advenimiento de La Edad de Oro de la Microbiología, en la que los agentes patógenos de muchas enfermedades sistémicas fueron identificados. McLean y Wade $(3,4)$ afirman que la cavidad oral humana es una de las comunidades microbianas mejor estudiadas gracias a su facilidad de acceso y se reconoce que posee una extraordinaria complejidad al albergar uno de los más diversos microbiomas del cuerpo humano, con la presencia de virus, hongos, protozoos, arqueas y más de 1000 especies bacterianas diferentes.

Fue Willoughby Dayton Miller (5) quien en 1880 definió la caries dental como una enfermedad mediada por bacterias. Cien años después, Walter Loesche (6) enunció que la caries es, por definición, "una infección endógena", ya que las bacterias que se relacionan con su etiología forman parte de la microbiota natural o biota indígena del ser humano y son residentes habituales de la cavidad oral desde el nacimiento hasta la muerte, como lo demuestra el hecho, según Cvitkovitch et al. (7), de que tan pronto como el Streptococcus mutans es detectado en el infante, persiste como un residente habitual, no letal, de la microflora oral.

Sin embargo; de acuerdo con Loesche (8), la sola presencia de los microorganismos no es suficiente para que se desarrolle la enfermedad, debido a que la caries dental es de tipo "sitioespecífico". En efecto; el prodigioso proceso de evolución adaptativa o resiliencia bacteriana es el principal factor que ha permitido su supervivencia a través de los siglos, merced a la alteración de las complejas relaciones e interrelaciones bacteriabacteria y bacteria-huésped en el ecosistema oral, a través de la ruptura del delicado equilibrio u homostasis que existe entre los diferentes hábitats: dientes, lengua, periodonto, saliva, encía libre, encía adherida, etc. La composición microbiana y su virulencia dependen entonces de las características ecológicas propias de cada uno 
de esos hábitats, 10 que incluye diferentes tipos de bacterias, con propiedades metabólicas y de crecimiento particulares.

Paul Keyes (9), connotado investigador de los años 60 del Instituto Nacional de Investigación Dental, Departamento de Salud de Estados Unidos, consideró que la caries dental es el resultado de la conjunción de una variedad de determinantes y bajo esa premisa, propuso un simple pero revolucionario modelo en el que, inicialmente, interactuaban tres agentes o factores etiológicos: huésped, microorganismos y la dieta. Desde entonces, los modelos de multicausalidad se han vuelto cada vez más complejos al írseles adicionando nuevos elementos que consideran desde las ciencias básicas, la microbiología e histopatología de los tejidos dentales hasta la genética, la ingeniería y reparación tisular, las ciencias sociales y del comportamiento.

Estos modelos de multicausalidad han generado, a su vez, novedosas propuestas para cuantificar la condición de riesgo de las distintas poblaciones, que sirve para determinar o predecir la posibilidad de aparición de nuevas lesiones cariosas. La importancia de esta predicción resulta obvia si se considera que las acciones preventivas individuales o comunitarias pueden dirigirse de manera puntual y precisa hacia los sujetos de alto riesgo, maximizando los recursos económicos y humanos disponibles.

Featherstone et al. (10) han propuesto que debe establecerse si existe -o no- equilibrio dinámico entre dos grandes grupos de factores: los benéficos o protectores y los de riesgo cariogénico 0 enfermantes. Entre los benéficos 0 protectores destacan la exposición a la lactancia materna, el acceso a los fluoruros, el uso de sellantes, agentes remineralizantes y antibacterianos, calidad y cantidad de flujo salival, una dieta saludable, etc. Entre los de riesgo cariogénico se ubican las bacterias acidógenas (productoras de ácidos), acidúricas (ácido tolerantes) y acidófilas (las que crecen y se reproducen en ambiente ácido), presencia de hábitos alimentarios 0 de higiene oral deletéreos, bajo flujo salival, etc. Lo anterior se complementa con valiosa información procedente de la historia médica y dental presente y pasada y de un minucioso y detallado examen clínico que registra todas las lesiones cariosas -desde las pérdidas minerales iniciales hasta las más extensas cavitaciones-, así como la presencia de defectos del desarrollo, experiencia previa de caries, presencia de restauraciones recientes, etc.

Con base en los anteriores elementos y tomando en consideración las expectativas del paciente, el clínico debe utilizar su experiencia y criterio clínico para ponderar el verdadero valor que cada factor desempeña en la red de multicausalidad. Para la Odontología de punta, la cuantificación de la condición de riesgo es un requisito previo indispensable para tomar acertadas decisiones individualizadas según cada condición particular para planificar: la prevención; la intervención sin invasión; el tratamiento conservador con mínima invasión y el seguimiento del caso, estableciendo el mejor pronóstico a largo plazo.

La creación e implementación del Sistema Internacional de Detección y Valoración de Caries, ICDAS por sus siglas en inglés (International Caries Detection and Assessment System), se ha ido posicionando gracias a su gran aceptación mundial, por la versatilidad de su uso en estudios de validación, sobre factores de riesgo, de vigilancia epidemiológica y en ensayos clínicos. El sistema permite no solo diferenciar las superficies dentales sanas de las enfermas, sino también conocer el grado de compromiso estructural (sin cavitación, con cavitación); establecer su estado de actividad (lesión activa 0 detenida); valorar el 
estado de integridad física de las restauraciones presentes; detectar la presencia de lesiones cariosas secundarias; establecer el diagnóstico diferencial en relación con otro tipo de alteraciones y seleccionar el mejor tratamiento.

Para facilitar la transmutación del paradigma de la antigua Cariología, centrada en el modelo restaurador, hacia uno moderno que tome como eje de su accionar la salud oral y la máxima preservación de los tejidos y las estructuras dentales, recientemente Pitts \& Ekstrand (11) han propuesto una guía denominada Sistema Internacional de Clasificación y Manejo de Caries -ICCMSTM -, la que es útil tanto en la práctica clínica como en la enseñanza y como modelo de inclusión social para un mejor abordaje de la salud oral en las comunidades. Considera cuatro elementos: historia médica y dental y valoración del nivel o condición de riesgo; la clasificación 0 detección de las lesiones cariosas en cada superficie dental y la valoración de su actividad mediante el sistema ICDAS; la decisión de manejo -síntesis- y diagnóstico que combina los hallazgos clínicos con la condición de riesgo para establecer el plan de tratamiento y los intervalos de control periódico y el manejo, en el que las decisiones clínicas relativas a la prevención, al tratamiento conservador no operatorio de las lesiones no cavitadas y el operatorio conservador de las lesiones de caries cavitadas y/o profundas en dentina son individualizadas, y se ajustan al riesgo de caries. La atención preventiva, de menor a mayor complejidad considera: A. El plan 0 programa preventivo básico B. El plan o programa preventivo adicional $C$. Tratamientos mínimamente invasivos D. Tratamientos invasivos E. monitoreo y revisión 0 control.

¿Qué debemos los odontólogos conocer en profundidad sobre la caries? Cómo ocurren las lesiones cariosas.

¿Qué debemos aprender a manejar e interpretar? Los fenómenos que ocurren entre el esmalte, la dentina y el cemento radicular y los depósitos orgánicos en forma de restos alimenticios y las interrelaciones que se establecen entre los tejidos dentales y los microorganismos que colonizan y entre las propias bacterias.

¿Es posible llegar a tener control sobre la caries dental? Ello no depende del dominio de ningún sistema político, económico o social, sino de la profunda comprensión -por parte de los profesionales en salud- de los fenómenos involucrados en su aparición y el compromiso ineludible de la profesión para educar e informar a la ciudadanía, utilizando todas las estrategias mencionadas desde el embarazo, la primera infancia y a través de toda la vida. 


\section{REFERENCIAS}

1. Centers for Disease Control (CDC) and Prevention, USA. Preventing Dental Caries with Community Programs. Division of Oral Health, National Center for Chronic Disease Prevention and Health Promotion. Page last updated: July 10, 2013.

2. Slavkin HC. Biofilms, microbial ecology and Antoni van Leeuwenhoek. J Am Dent Assoc. 1997 Apr;128(4):492-5.

3. McLean JS. Advancements toward a systems level understanding of the human oral microbiome Front Cell Infect Microbiol. 2014; 4: 98 doi: 10.3389/fcimb.2014.00098

4. Wade WG. The oral microbiome in health and disease. Pharmacological Research 2013; 69: 137-143.

5. Miller WD. The microorganisms of the human mouth.The SS White Manufacturing Philadelphia, 1890.

6. Loesche WJ. Role of Streptococcus mutans in human dental decay. Microbiological Reviews 1986,50(4):353-380.
7. Cvitkovitch DG, Li YH, and Ellen RP. Quorum sensing and biofilm formation in Streptococcal infections. J Clin Invest. 2003 Dec 1;112(11):1626-1632. doi: 10.1172/ JCI200320430.

8. Loesche WJ. Clinical and microbiological aspects of chemotherapeutic agents used according to the specific plaque hypothesis. J Dent Res. 1979; 58(12):2404-12.

9. Keyes PH. The infectious and transmissible nature of experimentaldentalcaries: findings and implications. Archives of Oral Biology 1960;1:304-320.

10. Featherstone JDB, Domejean-Orliaguet $\mathrm{S}$, Jenson L, Wolff M, and Young DA. Caries Risk Assessment in Practice Ages 6 Through Adult. J Calif Dent Assoc 2007;35(10):703-13.

11. Pitts NB, Ekstrand KR. International Caries Detection and Assessment System and its International Caries Classification and Management System (ICCMS)- methods for staging of the caries process and enabling dentists to manage caries. Community Dent Oral Epidemiol 2013; 41:e41-e52.

\section{Sylvia Gudiño Fernández DDS, MPH'; Eduardo Julio Lanata DDS, PhD²}

1. Profesora Catedrática, Departamentos de Odontopediatría y Odontología Social y Posgrado en Odontopediatría, Facultad de Odontología, Universidad de Costa Rica, Costa Rica. 2. Profesor Titular Consulto de la Cátedra de Técnica de Operatoria Dental de la Facultad de Odontología de la Universidad de Buenos Aires, Argentina.
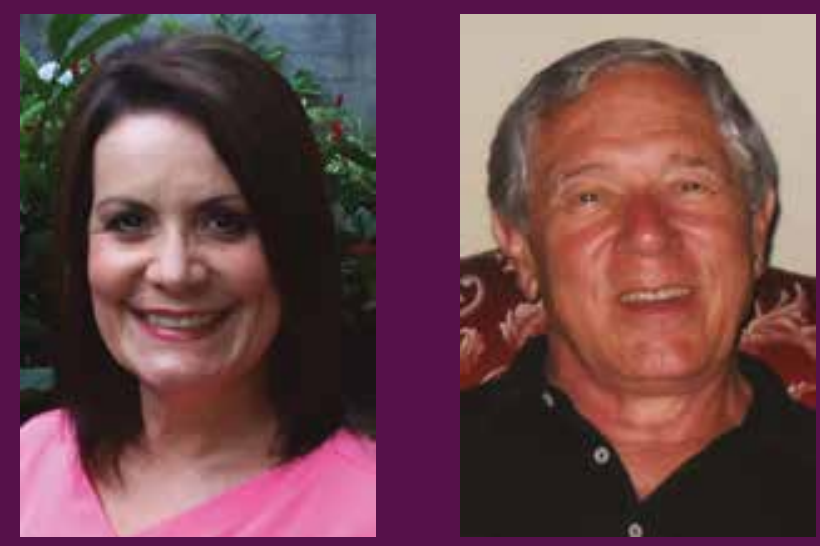